\title{
МЕНЕДЖМЕНТ
}

\section{И.И. Огородникова}

\section{ЦИФРОВАЯ ТРАНСФОРМАЦИЯ НАЛОГОВОГО КОНТРОЛЯ: ЭВОЛЮЦИЯ И ТЕНДЕНЦИИ}

\begin{abstract}
Глобальное всемирное погружение в циирровые технологии дает колоссальное преимущество в осуществлении и совершенствовании контрольно-надзорной деятельности государства. С момента возникновения налоговой службы в Российской Федерачии на постоянной основе проводится автоматизация мероприятий налогового контроля. Модернизация и трансформащия IT-технологий расширяет возможности налоговых сервисов и усиливает влияние налоговой службы на налогоплательщиков. Постепенно создается некая «адаптивная платформа» налогового администрирования, которая начинает работать исключительно с иифровыми источниками данных и с ирировыми идентичностями налогоплательщиков, оперирующая в режиме реального времени и со встроенным налоговым комплаенсом.

Ключевые слова: налоговый контроль, автоматизированные информационные системы, искусственный интеллект, ичировые технологии.
\end{abstract}

Методология. Данное исследование базируется на гипотезе: поэтапное внедрение цифровых технологий направлено на реализацию государством контрольно-надзорной функции и способствует эффективности проведения налогового контроля. Активное применение IT-технологий и искусственного интеллекта в налоговом администрировании осуществляется в настоящее время во многих странах мира. Цель исследования заключается в изучении становления автоматизированного контроля в налогообложении и распространении положительного российского и зарубежного опыта по применению цифровых технологий в налоговом администрировании. Объект исследования - налоговый контроль. Для повышения качества результатов исследования были выбраны те критерии анализа, которые позволяют получить достоверную информацию. Особое внимание уделяется текущему состоянию использования цифровых технологий, в частности искусственного интеллекта налоговыми службами в российской и зарубежной практике.

Исследованием аспектов применения цифровых технологий в налоговом администрировании занимаются во всем мире. Использование цифровизации начинается с момента внедрения компьютерных технологий в учет и аудит. Основой для технологических систем становится знание и информация, которая обрабатывается организацией для ведения бухгалтерского учета. В 70-х гг. XX в. в исследованиях Перроу отмечается важ- 
ность применения технологии в учете и аудите, исследуется влияние технологии на работу организации. В представленных работах анализируются информационные системы (IT) в качестве основы для проведения анализа деятельности организации. В 1978 г. Daft и Macintosh, основываясь на работах Перроу, представили резюме некоторых аспектов и классифицировали различные типы информационных технологий в учете [1].

Изучению IT-технологий, искусственного интеллекта в налогообложении посвящены работы Р. Черняховской, А. Исмагиловой. Перспективным направлением в налоговом администрировании являются разработки интеллектуальных экспертных систем на базе нейросетевого моделирования. Данные исследования проводились А. Бирюковым [2]. Объединение совместных усилий налоговых органов и IT-специалистов позволит создать систему, которая будет включать в себя преимущества основанных на использовании тематических и нейронных сетей. Такая технология, базирующаяся на алгоритмах, предоставит налоговым инспекторам глобальную динамичную платформу налоговой оценки, способную оспаривать суждения налогоплательщиков и точно предлагать дальнейшие действия по сбору доказательной базы.

Отдельные вопросы совершенствования методов налогового контроля через внедрение автоматизированных систем рассматривали Г. Жилин, И. Майбуров [3].

Эффективность налогового контроля предполагает максимальное поступление налоговых платежей при минимальных затратах. Поэтому вопрос введения автоматизированной информационной системы (АИС) решался кардинально и быстро. Например, создание и внедрение в 90-х гг. $\mathrm{XX}$ в. АИС, которая аккумулировала на первоначальном этапе в единое информационное пространство всевозможные государственные регистрационные службы и банковские учреждения. Компьютерные программы с широким диапазоном и набором функциональных операций были и остаются эффективными в проведении налогового контроля вне времени. Применение разнообразных электронных данных, облачных систем и компьютерных алгоритмов уже признано и оценено налоговыми администрациями Соединенного Королевства, Дании и Канады в качестве эффективного инструмента налогового администрирования.

Изначально использование автоматизированной системы «Налог» было направлено на решение простых задач, связанных с созданием централизованной базы и частной обработки полученной информации. Но технически возникали сложности, информационной и операционной системами компьютеров. Поэтому использование различных прикладных систем приводило к определенным проблемам:

- несогласованности и разному типу данных, т.е. базы данных одной прикладной системы нельзя было без специального конвертирования использовать другой системой;

- отсутствию единых процедур, которые использовались бы всеми государственными налоговыми инспекциями (так именовалась Федеральная 
налоговая служба ранее) для обработки налоговых деклараций и платежных документов, взысканий недоимки, контроля за соблюдением налоговой дисциплины, выбора плательщиков для проверки и др.;

- недостаточной степени стандартизации отчетности;

- существенным затратам на сопровождение и модернизацию прикладных систем [4, 5].

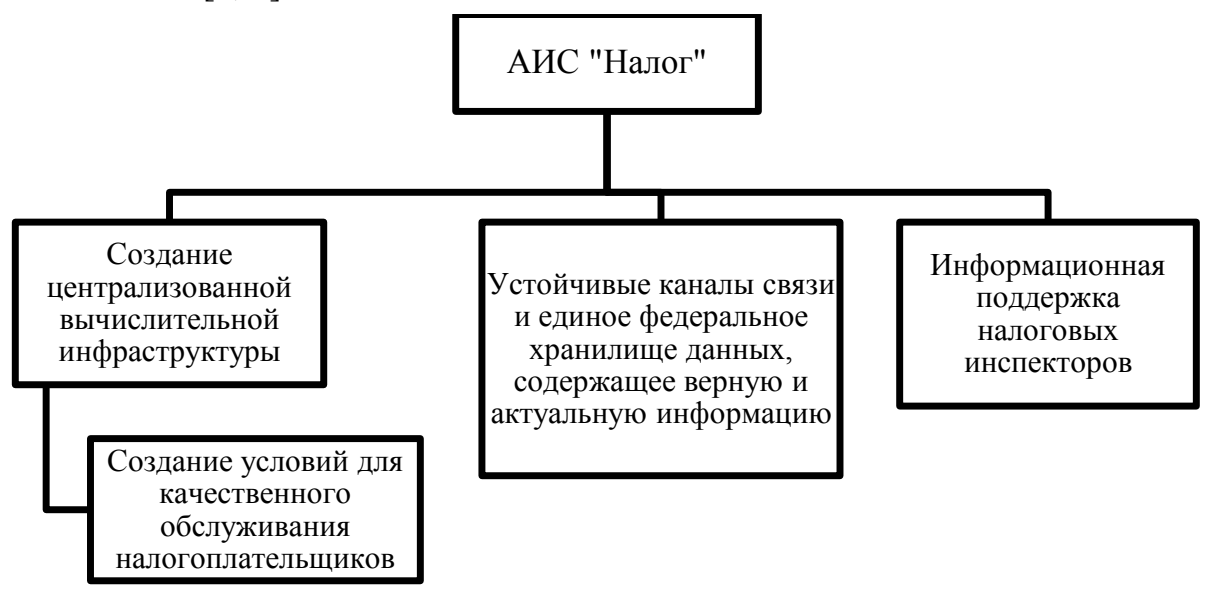

Рис. 1. Модель автоматизированной информационной системы «Налог»

Основная цель разработки и совершенствования автоматизированной информационной системы налоговых органов в 90-х гг. ХХ в. - внедрение функционально полной информационной технологии, объединяющей все структурные подразделения на базе единой вычислительной сети, интегрированной в единое информационное пространство органов государственного управления и других заинтересованных организаций (ГУВД, суды, таможня, банки и др.) [6].

В настоящее время в связи с повсеместным переходом человечества к цифровому обществу информационные технологии стали очень активно использоваться во всех сферах жизнедеятельности. Но все преимущества, которые предоставляют IT-технологии и искусственный интеллект, обусловлены высокими расходами, связанными с разработками и внедрениями соответствующих технологий. Прогнозируется стремительный рост расходов на внедрение когнитивных систем и технологий АI (рис. 2).

И тем не менее правительства разных стран мира все быстрее переходят на цифровые технологии. Согласно докладу Всемирного банка о мировом развитии «Цифровые дивиденды» (2016) в развивающихся странах количество рабочих мест с интенсивным использованием ИКТ выше в государственном, нежели в частном секторе. В 2014 г. 190 государств-членов (по данным ООН) внедрили автоматизированное управление финансами, 179 использовали такие системы для таможенного оформления, а 159 - для налогового администрирования. 148 из них внедрили ту или иную форму цифровой идентификации [8]. 


\section{РАСХОДЫ НА ВНЕДРЕНИЕ КОГНИТИВНЫХ СИСТЕМ И ТЕХНОЛОГИЙ ИСКУССТВЕННОГО ИНТЕЛЛЕКТА \\ В 2015-2020 ГОДАХ (\$ МЛРД) источник: IDC, июнь 2017.}

ПРОГНОЗ

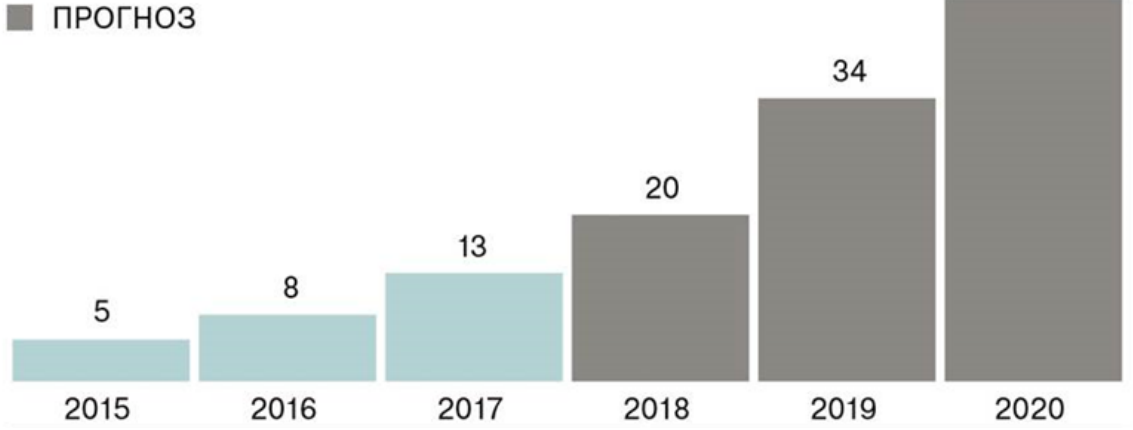

Рис. 2. Расходы на внедрение технологий искусственного интеллекта [7]

В России государственные контрольно-надзорные органы также активно усовершенствуют IT-технологии при проведении контрольных мероприятий. Выполнение дорожной карты по оптимизации контрольнонадзорной и фискальной функций государства предусматривает поэтапный переход к осуществлению мероприятий по проведению налогового контроля с использованием автоматизации и компьютеризации процессов. Осуществление контрольными органами с определенной периодичностью налоговых проверок налогоплательщиков зачастую требует повышения эффективности задействованных ресурсов, а количество налогоплательщиков превышает потенциальные возможности налоговых органов по проведению проверок налогоплательщиков. Применение же цифровых технологий позволяет освобождать налоговиков от рутинных операций и вытесняет коррупционную составляющую, исключая влияние человеческого фактора посредством использования личных контактов.

Кроме того, налогоплательщики сами активно используют информационные ресурсы Федеральной налоговой службы (рис. 3).

Федеральная налоговая служба России, подводя итоги периода 20152017 гг., отмечает тот факт, что в стране удалось повысить налоговые начисления и эффективно снизить задолженность по налогам с помощью ITтехнологий, которые внедряли в этот период времени. Такие системы, как АСК НДС, ЕГАИС, онлайн-кассы, маркировка товаров, администрирование иностранных поставщиков электронных услуг, способствовали увеличению поступления налогов на общем фоне относительной стагнации экономики, а задолженность по налогам за 2017 г. удалось снизить в 5 раз.

Успешно действует система АСК НДС-2, которая позволяет выстраивать цепочки формирования добавленной стоимости и автоматически пресекать уклонение от уплаты налога на добавленную стоимость или попытки мошеннического возмещения налога. За период действия системы (с 
2015 г.) количество фиктивных компаний сократилось более чем в 2 раза, а количество случаев заявления возмещение НДС высокорисковыми организациями - почти в 15 раз [10]. Когда в 2015 г. стали предоставлять налоговую декларацию по НДС с одновременным предоставлением книги покупок и книги продаж, то резко снизилось количество организаций, активно работающих нелегально в секторе теневой экономики. Выявлено, что при относительном спаде экономики в стране суммы налоговых поступлений по НДС были увеличены по сравнению с предшествующим периодом (таблица).

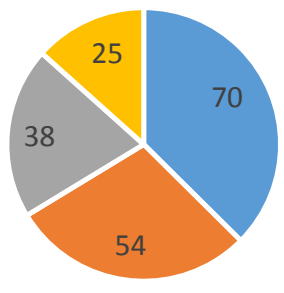

- "Проверь себя и контрагента"

- "Узнай свою задолженность"

- "Адрес вашей инспекции"

- "Личный кабинет"

Рис. 3. Популярные интернет-сервисы в 2017 г., млн чел. [9]

Соотношения роста ВВП и НДС за период 2014-2016 гг., млрд руб. $[9,11]$

\begin{tabular}{c|c|c|c|c|c}
\hline \multirow{2}{*}{ Показатель } & \multirow{2}{*}{2014} & \multirow{2}{*}{2015} & \multirow{2}{*}{2016} & \multicolumn{2}{|c}{ Динамика роста, \% } \\
\hline ВВП & 79199.7 & 83232.6 & 86043.6 & 105 & 103 \\
\hline $\begin{array}{l}\text { НДС, причитающий- } \\
\text { ся к уплате в бюджет }\end{array}$ & 3928.2 & 4430.9 & 4783.5 & 113 & 108 \\
\hline Доля НДС в ВВП, \% & 4.96 & 5.32 & 5.56 & 107 & 105 \\
\hline
\end{tabular}

При росте ВВП на 5\% в 2015 г. сумма НДС, причитающегося к уплате в бюджет, увеличилась на 13\% по сравнению с предыдущим периодом (2014 г.). В данный момент внедряется и усовершенствованная автоматизированная система «Налог-3». База общефедеральная, единая и в свободном доступе у всех налоговых инспекций в он-лайн режиме, что обеспечивает высокую собираемость налогов посредством применения автоматизированного контроля, мобильность и прозрачность. В частности, в рамках проведения камеральных налоговых проверок по НДС система АСК НДС-2 при выявлении расхождений по счетам-фактурам контрагентов без участия налогового инспектора делает запрос банковской выписки, значит, автоматически может выявлять налоговые правонарушения.

Прорывные технологии, которые помогут в построении будущих систем налогового администрирования, включают базы данных, именуемые Big Data, и их аналитику в реальном времени. Рассматриваются в перспективе создание единого файла налогоплательщика; «умные» порталы как единая точка доступа к услугам; мобильные технологии; искусственный 
интеллект. Задачей специалистов является создание наиболее оптимальных решений искусственного интеллекта, бесперебойной работы с базой данных. Аналитики играют огромную роль в налоговом контроле, потому что без данных или с некорректными данными искусственный интеллект бесполезен (рис. 4). Важно, чтобы аналитики знали не только методы манипулирования данными, но и аспекты налогообложения, к которым относятся эти данные. Часто только опытный человек может правильно читать данные, делать выводы и предлагать, как лучше всего использовать полученную информацию. По данным Министерства финансов РФ в течение 2017 г. было открыто более 11 тыс. вакансий в налоговое ведомство специалистов для разработки новых автоматизированных систем [12].

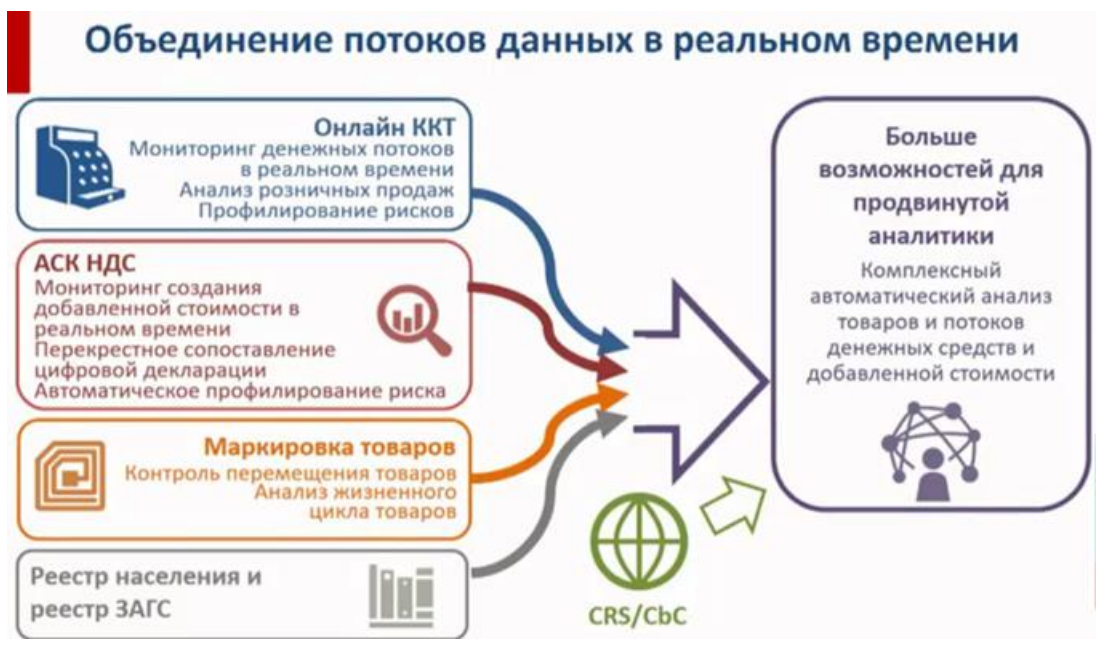

Рис. 4. Направления использования IT-технологий в налоговом контроле

В 2018 г. Федеральная налоговая служба успешно реализовала основной этап реформы онлайн-касс. В результате свыше 856 тыс. организаций и индивидуальных предпринимателей, работающих в сфере торговли и общественного питания, подключили к системе 2,3 млн онлайн-касс. В сутки пробивается 120 млн чеков на сумму 70 млрд руб. «Средняя выручка на одну кассу увеличилась в два раза, а розничная торговля в 2017 году демонстрирует рост НДС на $38 \%$ по сравнению с предыдущим годом», - констатировал Михаил Мишустин [14]. Количество проведенных проверок применения контрольно-кассовой техники и полноты учета выручки по итогам 2017 г. снизилось в 2 раза по сравнению с 2016 г. В 2018 г. ФНС обеспечила дальнейшее снижение количества проверок: в первом полугодии 2018 года было проведено менее 11 тысяч проверок. Это в 4,5 раза меньше аналогичного периода 2017-го [14]. Система онлайн-касс основывается на технологии «интернета вещей» и аналитики Big Date. Информация о расчетах передается в адрес налоговых органов в режиме реального времени, тем самым предотвращает мошенничество и позволяет 
автоматически оценивать риски, что, в свою очередь, снижает необходимость проведения налоговых проверок.

В 2014 г. Бюро Форума по налоговому администрированию ОСЭР обратилось к ФНС России с просьбой возглавить работу по предоставлению электронных сервисов налогоплательщикам и развитию цифровых каналов доставки услуг. Используя накопленный опыт и применение цифровых технологий в России, была подготовлена и издана публикация «Технологии для лучшего налогового администрирования» под эгидой ОСЭР. В Сингапуре на семинаре в 2017 г. принимали участие представители известных цифровых брендов - IBM, Microsoft, EY и Teradata. Обмениваясь опытом, ФНС России представила технологию онлайн-ККТ. Применяемая технология, что примечательно, позволяет привлекать к контролю покупателей, потому как с помощью мобильного приложения, которое закачивается в телефон или мобильное устройство, можно проверить легальность выданного чека. На текущий момент граждане Российской Федерации успешно проверили около 30 млн чеков [15].

Но использование цифровых технологий имеет отдельные недостатки. Так, Национальная комиссия по информатике и свободам (CNIL) во Франции, являющаяся независимым административным органом, охраняющим личные данные, подчеркивает значимость защиты персональной информации. Внедрение цифровых технологий потребует «значительного расширения обработки информации, поскольку все французские налогоплательщики будут затронуты» и соответственно этот процесс должен сопровождаться «надлежащими гарантиями». Вместе с тем ясно, что, несмотря на рекомендации CNIL, налоговая служба выступает за сохранение механизма тотальной обработки информации. Если налоговое управление будет следовать требованиям «надлежащих гарантий» со стороны государства, то можно будет обеспечить баланс между защитой персональных данных и эффективностью налоговых служб и налогового контроля [16].

Накануне Дня защиты персональных данных, традиционно отмечаемого 28 января, в 2019 г. Совет Европы опубликовал «Руководящие принципы по защите персональных данных при использовании искусственного интеллекта» (Guidelines on Artificial Intelligence and Data Protection). Документ содержит три блока рекомендаций: общие принципы; принципы для разработчиков, производителей и сервис-провайдеров; принципы для законодательных и исполнительных органов власти.

Часть из общих принципов защиты персональных данных при использовании технологий искусственного интеллекта заключается в нижеследующем:

1. Защита человеческого достоинства и охрана прав человека и фундаментальных свобод, в особенности право на защиту персональных данных, являются основой при разработке и внедрении ИИ-приложений, которые могут повлиять на отдельных людей и общество. Это особенно важно, когда ИИ-приложения используются в процессах принятия решений.

2. Разработка ИИ, основывающегося на обработке персональных данных, должна базироваться на принципах «Конвенции 108+». Ключевыми 
элементами такого подхода являются: законность, беспристрастность, конкретизация целей, «пропорциональность» (разумные ограничения, вытекающие из решаемых задач) обработки данных, встроенный алгоритм конфиденциальности, ответственность и демонстрация соблюдения регулятивных требований (контролируемости), прозрачность, защита данных и риск-менеджмент.

3. Подход, сфокусированный на профилактике и устранении потенциальных рисков обработки персональных данных, является необходимым элементом «ответственных инноваций» в сфере искусственного интеллекта [17].

С другой стороны, можно сказать, что искусственный интеллект играет огромную роль в защите персональных данных. Обнаружение мошенничества на основе решений с искусственным интеллектом поможет сократить киберпреступления. Это связано с тем, что ИИ-инструменты могут получать данные в режиме реального времени с различных баз данных и моментально их анализировать. Человеку такое физически непосильно.

Заключение. В последние годы фискальное ведомство активно внедряет цифровые технологии в налоговое администрирование. Уже создана мощная технологическая база, развиваются и расширяются электронные сервисы (личный кабинет налогоплательщика, налоговый калькулятор для расчета налога и т.п.). Благодаря системам АСК НДС, ЕГАИС и АСК ККТ в несколько раз сократилось число налоговых проверок, при этом увеличилась сумма поступивших налогов и штрафов. Цифровые технологии делают выполнение требований налогового законодательства частью естественной среды налогоплательщика, а налоговое администрирование станет практически незаметным. Повышение объемов информационных потоков приведет мировое сообщество к полной финансовой прозрачности в ближайшем будущем.

Отрадно, что передовой опыт России применения цифровых технологий в налоговом администрировании используется в зарубежных странах. Конечно, одним из важнейших этапов процесса разработки параметров цифровой трансформации является четкое целеполагание и адаптация ее задач под стратегические цели налоговой администрации. Также важно учитывать и по возможности снижать издержки бизнеса, связанные с переходом на новую систему цифровизации налогового контроля.

И на подходе новые технологии - наиболее распространенной в ближайшие несколько лет станет система идентификации «все-в-одном», которая одновременно распознает несколько биометрических параметров, в частности, отпечатки пальцев, сетчатку глаза и голос. Примером такой технологии является Fusion Engine, разработанная для смартфонов компаниями Synaptics и KeyLemon. Искусственный интеллект и когнитивные технологии, робототехника уже широко используются в управлении рисками, клиентскими коммуникациями, идентификацией подлинности, борьбе с отмыванием денег и в других операционных процессах. В отделениях канадского банка ATB Financial с клиентами общается гуманоид по имени Pepper, разработанный SoftBank Robotics Corp. 
Bank of Tokyo-Mitsubishi UFJ (MUFG) представил 58-сантиметрового робота Nao, который может распознавать 19 разговорных языков, взаимодействовать и общаться с клиентами в филиалах, а также отвечать на их запросы $[18,19]$. В будущем искусственный интеллект способен заменить человеческий ресурс прежде всего в таких направлениях, как обработка платежей и документов, оценка кредитоспособности и рисков, HR, анализ данных. А это новое направление в цифровых трансформациях, которые могут быть использованы и в мероприятиях налогового контроля.

Цифровая трансформация существенно меняет и укрепляет техническую оснащенность Федеральной налоговой службы. Запущенные и успешно реализованные проекты существенно снижают нагрузку на налоговых инспекторов и повышают эффективность налогового контроля, что, в свою очередь, выражается в увеличении налоговых поступлений в бюджет.

Процесс автоматизации налогового контроля эволюционирует и двигается быстрыми темпами, учитывая современные тренды мировой цифровизации. Передовые IT-технологии налогового контроля, разработанные в России, применяются в других странах. Направления и скорость преобразований налогового администрирования в ближайшем будущем будут совершенствоваться и подстраиваться уже под новые инновационные технологические процессы.

\section{Лumepamypa}

1. O'Learyt D.E., $O^{\prime}$ Keefe R.M. The Impact of Artificial Intelligence in Accounting Work: Expert Systems Use in Auditing and Tax // AI \& Soc Springer-Verlag London Limited. 1997. № 11. P. 36-47.

2. Бирюков А.Н. Обзор и анализ возможностей интеллектуального моделирования в бюджетно-налоговой системе регионального и муниципального уровней: Бюджетноналоговое администрирование: нейросетевые методы исследований. М. : НИИ истории, экономики и права, 2018. $147 \mathrm{c}$.

3. Жилин Г.О., Майбуров И.А. Совершенствование методов налогового контроля: внедрение автоматизированных систем // Актуальные проблемы налоговой политики : сб. материалов IX Международной научно-практической конференции молодых налоговедов. ДВФУ: Школа экономики и менеджмента, 2017. С. 117-119.

4. Гончаренко Л.И., Малкова Ю.В., Адвокатова А.С. Актуальные проблемы налоговой системы в условиях цифровой экономики. Финансовый университет, Департамент налоговой политики и таможенно-тарифного регулирования Финансового университета, 2018. URL: https://cyberleninka.ru/article/v/aktualnye-problemy-nalogovoy-sistemy-vusloviyah-tsifrovoy-ekonomiki (дата обращения: 30.01.2019).

5. Черник Д.Г., Морозов В.П., Лобанов А.В. Технология налогового контроля // Налоговый вестник. 2000. № 5. C. 3. URL: http://www.nalvest.ru/nv-articles/detail.php?ID= 23977 (дата обращения: 30.01.2019).

6. Введение в экономико-математические модели налогообложения : учеб. пособие / под ред. Д.Г. Черника. М. : Финансы и статистика, 2000. 256 с.

7. Global FinTech survey China Summary. 2017. URL: https://www.pwccn.com/en/ financial-services/publications/fintech/global-fintech-survey-china-summary-jun2017.pdf

8. Digital dividend. World Bank review. LNCS Homepage. URL: https://openknowledge.worldbank.org, last accessed 2018/12/14

9. Офищиальный сайт Федеральной налоговой службы. URL: http://www.nalog.ru

10. Мишустин М. ФНС России использует прорывные технологии, чтобы соответствовать новым требованиям к налоговой системе. URL: https://www.nalog.ru/ rn77/news/activities_fts/ 6973314/ 
11. Официальный сайт Федеральной службы государственной статистики. URL: http://www.gks.ru

12. Налоговики набирают айтишников. URL: https://www.gazeta.ru/business/2016/ 12/29/10455299.shtml?updated\#page3

13. Информачионные технологии в Федеральной налоговой службе. URL: http://www.tadviser.ru/index.php

14. Глава ФНС подвел предварительные итоги 2018 года. URL: https://finance.rambler.ru/realty/41437818/?utm_content=rfinance\&utm_medium=read_more\&utm_source= copylink

15. Михаил Мишустин представил работу онлайн-касс на Форуме по налоговому администрированию ОЭСР в Венгрии. URL: https://www.nalog.ru/rn77/news/international_activities/7588882/

16. Обзор законодательства Франции. URL: Délibération $n^{\circ}$ 2017-226 du 20 juillet 2017:JO 14 novembre 2017

17. Экспертный центр электронного государства. URL: http://drussia.ru/konsultativnyj-komitet-soveta-evropy-deklariroval-obya zatel nost-zashhitypersonalnyh-dannyh-ot-posyagatelstv-ii.html

18. Artificial intelligence in banks. URL: http://www.tadviser.ru/index.php

19. Bui T. Banks 2020: revolution. URL: http://www.management.com.ua/ tend/tend959.html

\section{Digital Transformation of Tax Control: Evolution and Trends}

Vestnik Tomskogo gosudarstvennogo universiteta. Ekonomika - Tomsk State University Journal of Economics. 2019. 46. pp. 152-162.

DOI: $10.17223 / 19988648 / 46 / 10$

Irina I. Ogorodnikova, University of Tyumen (Tyumen, Russian Federation). E-mail: iogorodn@yandex.ru

Keywords: tax control, automated information systems, artificial intelligence, digital technologies.

Global immersion in digital technologies gives a huge advantage in the implementation and improvement of the control and supervisory activities of the state. Since the inception of the tax service in the Russian Federation, automation of tax control measures has been carried out on a regular basis. IT modernization and transformation expand the possibilities of tax services and enhance the impact of the tax service on taxpayers. Gradually, a kind of an "adaptive platform" of tax administration is being created, which begins to work exclusively with digital data sources and with taxpayers' digital identities and operate in real time with a built-in tax compliance.

\section{References}

1. O'Learyt, D.E. \& O' Keefe, R.M. (1997) The Impact of Artificial Intelligence in Accounting Work: Expert Systems Use in Auditing and Tax. AI \& Soc Springer-Verlag London Limited. 11. pp. 36-47.

2. Biryukov, A.N. (2018) Obzor i analiz vozmozhnostey intellektual'nogo modelirovaniya $v$ byudzhetno-nalogovoy sisteme regional'nogo $i$ munitsipal'nogo urovney: Byudzhetnonalogovoe administrirovanie: neyrosetevye metody issledovaniy [Overview and analysis of the possibilities of intelligent modeling in the fiscal system of the regional and municipal levels: Fiscal administration: neural network research methods]. Moscow: NII istorii, ekonomiki i prava.

3. Zhilin, G.O. \& Mayburov, I.A. (2017) [Improving the methods of tax control: the introduction of automated systems]. Aktual'nye problemy nalogovoy politiki [Topical issues of tax policy]. Proceedings of the IX International Conference of Young Tax Experts. FEFU: School of Economics and Management. pp. 117-119. (In Russian). 
4. Goncharenko, L.I., Malkova, Yu.V. \& Advokatova, A.S. (2018) Aktual'nye problemy nalogovoy sistemy $v$ usloviyakh tsifrovoy ekonomiki [Urgent problems of the tax system in the digital economy]. [Online] Available from: https://cyberleninka.ru/article/v/aktualnyeproblemy-nalogovoy-sistemy-v-usloviyah-tsifrovoy-ekonomiki. (Accessed: 30.01.2019).

5. Chernik, D.G., Morozov, V.P. \& Lobanov, A.V. (2000) Tekhnologiya nalogovogo kontrolya [Technology of tax control]. Nalogovyy vestnik. 5. pp. 3. [Online] Available from: http://www.nalvest.ru/nv-articles/detail.php?ID=23977. (Accessed: 30.01.2019).

6. Chernik, D.G. (ed.) (2000) Vvedenie $v$ ekonomiko-matematicheskie modeli nalogooblozheniya [Introduction to economic and mathematical models of taxation]. Moscow: Finansy i statistika.

7. PWCCN. (2017) Global FinTech survey. China Summary. [Online] Available from: https://www.pwccn.com/en/financial-services/publications/fintech/global-fintech-surveychina-summary-jun2017.pdf.

8. World Bank Group. (2016) Digital dividends. World Bank review. LNCS Homepage. [Online] Available from: https://openkno-wledge.worldbank.org. (Accessed: 14.12.2018).

9. The official website of the Federal Tax Service. [Online] Available from: http://www.nalog.ru.

10. Mishustin, M. (2017) FNS Rossii ispol'zuet proryvnye tekhnologii, chtoby sootvetstvovat' novym trebovaniyam $k$ nalogovoy sisteme [The Federal Tax Service of Russia uses breakthrough technologies to meet new requirements for the tax system]. [Online] Available from: https://www.nalog.ru/rn77/news/activities fts/6973314/.

11. The official website of the Federal State Statistics Service. [Online] Available from: http://www.gks.ru.

12. Gazeta.ru. (2016) Nalogoviki nabirayut aytishnikov [Tax officials are recruiting IT specialists.]. [Online] Available from: https://www.gazeta.ru/business/2016/12/29/ 10455299.shtml?updated\#page3.

13. Tadviser.ru. (n.d.) Informatsionnye tekhnologii v Federal'noy nalogovoy sluzhbe [Information technology in the Federal Tax Service]. [Online] Available from: http://www.tadviser.ru/index.php.

14. Rambler.ru. (2018) Glava FNS podvel predvaritel'nye itogi 2018 goda [The head of the Federal Tax Service summed up the preliminary results of 2018]. [Online] Available from: $\mathrm{https}$ ://finance.rambler.ru/realty/41437818/?utm_content= rfinance\&utm_medium=read_more \&utm_source $=$ copylink.

15. Nalog.ru. (2018) Mikhail Mishustin predstavil rabotu onlayn-kass na Forume po nalogovomu administrirovaniyu OESR v Vengrii [Mikhail Mishustin presented the work of online cash register at the OECD Tax Administration Forum in Hungary]. [Online] Available from: https://www.nalog.ru/rn77/news/interna-tional_activities/7588882/.

16. Legifrance. (2017) Délibération $n^{\circ}$ 2017-226 du 20 juillet 2017:JO 14 novembre 2017. [Online] Available from: https://www.legifrance.gouv.fr/affichTexte.do?cidTexte= JORFTEXT000036013019\&categorieLien=id.

17. D-Russia. (n.d.) Konsul 'tativnyy komitet Soveta Evropy deklariroval obyazatel'nost' zashchity personal'nykh dannykh ot posyagatel'stv II [Council of Europe Advisory Committee declares mandatory protection of personal data from AI attacks]. [Online] Available from: http://d-russia.ru/konsultativnyj-komitet-soveta-evropy-deklariroval-obya zatel nost-zashhitypersonalnyh-dannyh-ot-posyagatelstv-ii.html.

18. Tadviser.ru. (n.d.) Artificial intelligence in banks. [Online] Available from: http://www.tadviser.ru/index.php.

19. Bui, T. (2017) Banks 2020: revolution. [Online] Available from: http://www.management.com.ua/tend/tend959.html. 